\title{
ARTICLE
}

\section{Development of Dual Counting Analysis and Exposure Possibility Evaluation for Carbon-14 at Korean Nuclear Power Plants}

\author{
Tae Young KONG ${ }^{* 1}$, Hee Geun KIM ${ }^{1}$, Sang Jun HAN ${ }^{2}$, Goung Jin LEE ${ }^{2}$ \\ ${ }^{1}$ Korea Electric Power Research Institute, 103-16 Munji-dong, Yuseong-gu, Daejeon, 305-380, Korea \\ ${ }^{2}$ Chosun University, 375 Seosuk-dong, Dong-gu, Gwangju, 501-759, Korea
}

\begin{abstract}
In a Pressurized Heavy Water Reactor (PHWR), most internal radiation exposure is attributed to tritium. Carbon-14 is not a dominant nuclide in the radiation exposure of workers, but it is one of the potential nuclide that needs to be monitored. Carbon-14 is a low energy beta emitter and passes relatively easily into the body of workers by inhalation because its dominant chemical form is radioactive carbon dioxide $\left({ }^{14} \mathrm{CO}_{2}\right)$. Most inhaled carbon-14 is rapidly exhaled from the worker's body, but a small amount of carbon-14 remains inside the body and is excreted by urine. In this study, a method for dual analyzing tritium and carbon-14 in urine samples of workers at nuclear power plants was developed. As a result of the developed dual counting analysis of tritium and carbon-14 in the urine samples of radiation workers who entered the high radiation field area at a PHWR, it was found that internal exposure to carbon-14 is unlikely to occur. In addition, through the urine counting results of radiation workers who participated in the opening process of steam generators at pressurized water reactors (PWR), it was found that the likelihood of internal exposure to either tritium or carbon-14 is extremely low at PWR.
\end{abstract}

KEYWORDS: dual counting, internal dose assessment, carbon-14, tritium, liquid scintillation counter

\section{Introduction}

Internal exposure at Pressurized Heavy Water Reactors (PHWRs) accounts for approximately $30 \%$ of total radiation exposure, almost all of the internal radiation exposure is attributed to tritium. Radiation workers who have access to radiation controlled areas submit their urine samples to health physicists every fifteen days while additional urine samples are demanded from workers who do important work in high radiation exposure areas. ${ }^{1)}$ Carbon-14 is not a dominant nuclide in the radiation exposure of workers, but it is one potential nuclide that needs to be monitored. ${ }^{2)}$

At PHWRs, carbon-14 is generally produced by the irradiation of oxygen that is present as impurities in the moderator system from the ${ }^{17} \mathrm{O}(\mathrm{n}, \alpha){ }^{14} \mathrm{C}$ reaction. ${ }^{3)}$ Because the carbon-14 that is released from PHWRs mostly exists as carbon dioxide $\left({ }^{14} \mathrm{CO}_{2}\right)$, the carbon-14 that is released in the work area can be easily inhaled by the radiation workers into their bodies. ${ }^{1,2)}$ Most of the carbon-14 that is inhaled is rapidly exhaled from the worker's body, but a small amount of carbon-14 remains inside the body and is excreted by urine. ${ }^{1)}$ Since carbon-14 is a low energy beta emitter, internal dose assessment for carbon-14 is conducted by using the measurement results of carbon-14 in the urine samples of radiation workers.

In this study, the origin of carbon-14 and its metabolism through inhalation were reviewed for the internal dose assessment of carbon-14 at PHWRs. In particular, the method of dual counting analyzing tritium and carbon-14 in urine samples was developed with the use of Liquid Scintillation Counters (LSCs) and methods for tritium measurements at the Wolsong Nuclear Power Plants (NPPs).

*Corresponding Author, Tel. +82-42-865-5480, FAX.

+82-42-865-5412, E-mail: eagertae@kepri.re.kr

\section{Carbon-14 Production at NPPs}

In general, it is estimated that the annual amounts of carbon-14 that are produced are approximately $370 \mathrm{Ci}$ for a PHWR and $5 \sim 8 \mathrm{Ci}$ for a PWRs. ${ }^{3-6)}$ At PHWRs, carbon-14 is produced in the fuel, moderator, reactor coolant, and annulus gas systems by neutron activiation reactions between neutrons and the parent isotopes ${ }^{13} \mathrm{C},{ }^{14} \mathrm{~N},{ }^{17} \mathrm{O},{ }^{3,6,7)}$ These parent isotopes were involved in the three major types of reactions that produced carbon-14 at a $600 \mathrm{MWe}$ PHWR, as listed in Table 1.,7)

Table 1 Dominant Carbon-14 production mechanisms at PHWRs

\begin{tabular}{cccc}
\hline $\begin{array}{c}\text { Target } \\
\text { nuclide }\end{array}$ & $\begin{array}{c}\text { Natural } \\
\text { abundance }(\%)\end{array}$ & Reaction & $\begin{array}{c}\text { Thermal neutron } \\
\text { cross section }\end{array}$ \\
\hline${ }^{17} \mathrm{O}$ & 0.037 & ${ }^{17} \mathrm{O}(\mathrm{n}, \alpha){ }^{14} \mathrm{C}$ & 0.235 barn \\
${ }^{14} \mathrm{~N}$ & 99.63 & ${ }^{14} \mathrm{~N}(\mathrm{n}, \mathrm{p}){ }^{14} \mathrm{C}$ & 1.820 barn \\
${ }^{13} \mathrm{C}$ & 1.11 & ${ }^{13} \mathrm{C}(\mathrm{n}, \mathrm{\gamma}){ }^{14} \mathrm{C}$ & 0.009 barn \\
\hline
\end{tabular}

At PHWRs, the generation of carbon- 14 from ${ }^{13} \mathrm{C}$ is lower due to its low cross section of ${ }^{13} \mathrm{C}$ and its small concentration in the coolant. On the other hand, ${ }^{14} \mathrm{~N}$ has enough isotopic abundance and a high cross section, and thus it is possible to produce a large amount of carbon-14. However, the actual amount of carbon-14 production is small since the generation of carbon-14 from ${ }^{14} \mathrm{~N}$ primarily occurs in the annulus gas system. ${ }^{3)}$ Despite the low cross section and the small isotopic abundance of ${ }^{17} \mathrm{O}$ compared with ${ }^{14} \mathrm{~N}$, the oxygen reaction, ${ }^{17} \mathrm{O}(\mathrm{n}, \alpha){ }^{14} \mathrm{C}$, is the dominant carbon-14 production mechanism at PHWRs because a large amount of heavy water, including ${ }^{17} \mathrm{O}$, is used as a reactor coolant and moderator. ${ }^{3,6)}$ 


\section{Dual Counting Analysis of Tritium and}

\section{Carbon-14}

Liquid scintillation counting is generally used to measure the radioactivity concentration of carbon-14 in urine samples of radiation workers. ${ }^{1,6,8,9)}$ The effective radioactivity counting method in urine that is commonly used is to set the lower and higher energy channels of the Liquid Scintillation Counter (LSC) to rise and to fall, respectively, in order to detect the liquid scintillation that is released from only carbon-14 within a specific channel interval. Carbon-14 measurement is conducted with tritium simultaneously while a one-minute count is appropriate for detection. ${ }^{10)}$ In order to get a certain radioactive level, it is necessary to employ a longer counting time, approximately ten minutes, for carbon-14 measurements. ${ }^{6,11,12)}$

In order to develop the dual counting analysis method of tritium and carbon-14, measurement and analysis were performed with LSC and both artificial and real urine samples of the radiation workers. ${ }^{6,11,12)}$ Prior to the measurements, sensitivity analysis was conducted for each parameter, which can affect the counting results. After sensitivity analysis, effective channels of LSC were determined through the optimization process, which increased the effective count's maximum and reduced the background minimum. ${ }^{6,11,12)}$

The counting results of tritium and carbon-14 in urine samples that used an LSC are illustrated by channel counts in Fig. 1. Tritium has a continuous spectrum with a maximum energy of $18.6 \mathrm{keV}$, but after measuring the tritium spectrum by using an LSC, it was found that $86.5 \%$ of total spectrum was distributed lower than $4.0 \mathrm{keV}$. On the other hand, carbon-14 has a maximum energy of $156 \mathrm{keV}$ and, after measuring, it was found that $95.6 \%$ of total counts were distributed within $42 \mathrm{keV}$.

The effective channels of LSC were determined through the optimization process, which maximized the counting efficiency and reduced the Minimum Detectable Activity (MDA). ${ }^{6}$ First, in order to determine the lower channel, the higher channel was fixed at Channel 200. Then, the lower channel was increased gradually by one channel from Channel 1 in order to optimize the counting channels. Here, one channel is a unit that has $0.5 \mathrm{keV}$. On the other hand, in order to determine the higher channel, the lower channel was fixed at Channel 1 and then the higher channel was decreased gradually by one channel from Channel 200 in order to optimize counting channels that were similar to those in the previous process. In this process, the effective channels were determined by using the spectrums of both tritium and carbon-14 in order to maximize the counting efficiency and minimize the MDA. Fig. 2 and 3 show the determination process of creating effective channels for tritium and carbon-14, respectively. As a result, the effective channels were set from Channels 1 to 9 for single and dual counting analysis of tritium, from Channels 4 to 85 for single counting analysis of carbon-14, and from Channels 30 to 85 for dual counting analysis of carbon-14., ${ }^{2,6}$

A reliability test for the developed method of dual counting analysis was conducted by using standard samples that were made for the use of verification. In order to make standard samples, tritium was mixed at a level of radioactivity that was 100 times higher than that of carbon-14, with consideration of the practical levels of radioactivity in the urine samples from the NPPs. As a result of the reliability test, the results demonstrated good performance, showing that the mean values of analysis for tritium and carbon- 14 were almost similar to the calculated values, within $10 \%$ for tritium and $5 \%$ for carbon- 14 . The standard deviation of the measured values was regarded as appropriate, and was shown to be within $8 \sim 10 \%$ of the average measured values. ${ }^{6,11,12)}$

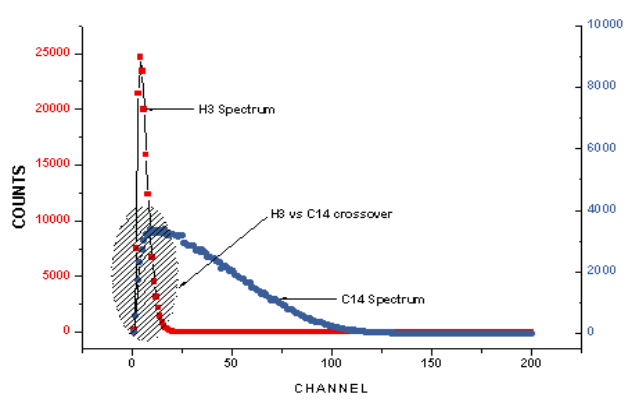

Fig. 1 Spectrum of tritium and carbon-14

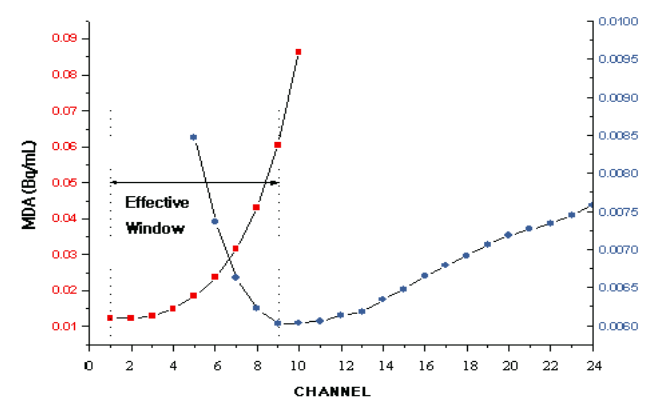

Fig. 2 Channel determination for the optimization of tritium analysis. " $\square$ " indicates a lower channel determination process. "•" indicates an upper channel determination process.

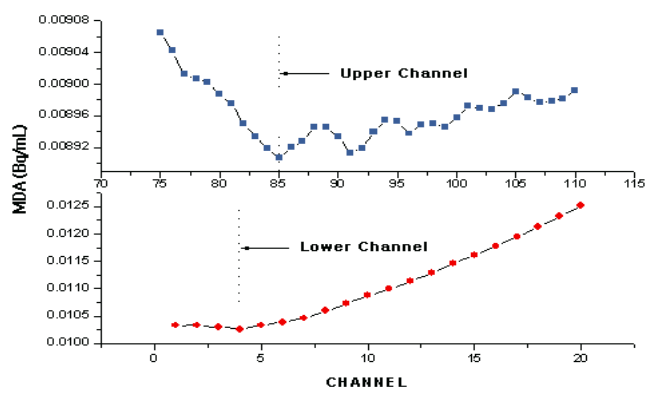

Fig. 3 Channel determination for the optimization of carbon-14 analysis 
Table 2 Tritium and Carbon-14 Analysis at PHWRs

\begin{tabular}{|c|c|c|c|c|c|c|c|c|c|c|}
\hline \multirow{2}{*}{ No. } & \multirow{2}{*}{$\begin{array}{c}\text { Given } \\
\text { Value } \\
(\mathrm{Bq} / \mathrm{mL})^{\mathrm{a}}\end{array}$} & \multicolumn{3}{|c|}{$\begin{array}{c}\text { Tritium Analysis } \\
\text { Windows: Channels } 1 \sim 9\end{array}$} & \multicolumn{3}{|c|}{$\begin{array}{c}\text { Carbon-14 Analysis } \\
\text { Windows: Channels } 4 \sim 85\end{array}$} & \multicolumn{3}{|c|}{$\begin{array}{c}\text { Carbon-14 Analysis } \\
\text { Windows: Channels 30 85 }\end{array}$} \\
\hline & & $\begin{array}{l}\text { Eff } \\
(\%)\end{array}$ & $\begin{array}{l}\text { Gross } \\
(\mathrm{Bq} / \mathrm{cc})\end{array}$ & $\begin{array}{c}\mathrm{Net}^{\mathrm{b}} \\
(\mathrm{Bq} / \mathrm{cc})\end{array}$ & $\begin{array}{l}\text { Eff } \\
(\%)\end{array}$ & $\begin{array}{l}\text { Gross } \\
(\mathrm{Bq} / \mathrm{cc})\end{array}$ & $\begin{array}{c}\mathrm{Net}^{\mathrm{b}} \\
(\mathrm{Bq} / \mathrm{cc})\end{array}$ & $\begin{array}{l}\text { Eff } \\
(\%)\end{array}$ & $\begin{array}{l}\text { Gross } \\
(\mathrm{Bq} / \mathrm{cc})\end{array}$ & $\begin{array}{l}\mathrm{Net}^{\mathrm{b}} \\
(\mathrm{Bq} / \mathrm{cc})\end{array}$ \\
\hline 1 & 120 & 28.68 & 116.68 & 116.44 & 88.85 & 31.59 & 31.29 & 38.26 & 0.30 & 0.00 \\
\hline 2 & 143 & 22.92 & 133.65 & 133.31 & 86.30 & 26.98 & 26.63 & 27.26 & 0.18 & 0.00 \\
\hline 3 & 11 & 29.76 & 12.38 & 12.11 & 88.80 & 3.78 & 3.44 & 40.42 & 0.41 & 0.04 \\
\hline 4 & 59 & 28.19 & 54.63 & 54.35 & 88.79 & 14.76 & 14.42 & 37.31 & 0.44 & 0.05 \\
\hline 5 & 40 & 27.80 & 37.72 & 37.46 & 88.72 & 10.28 & 9.97 & 36.55 & 0.66 & 0.29 \\
\hline 6 & 2 & 30.09 & 1.56 & 1.31 & 88.73 & 0.59 & 0.26 & 41.07 & 0.08 & 0.00 \\
\hline 7 & 127 & 26.00 & 120.45 & 120.16 & 88.11 & 29.57 & 29.23 & 33.07 & 0.49 & 0.05 \\
\hline 8 & 391 & 27.65 & 379.39 & 379.11 & 88.69 & 99.26 & 98.92 & 36.26 & 0.40 & 0.00 \\
\hline 9 & 68 & 27.17 & 70.73 & 70.49 & 88.56 & 18.26 & 17.97 & 35.33 & 0.28 & 0.00 \\
\hline 10 & 129 & 31.04 & 121.77 & 121.51 & 88.34 & 39.38 & 39.03 & 43.01 & 0.66 & 0.32 \\
\hline 11 & 104 & 27.61 & 91.43 & 91.15 & 88.68 & 24.50 & 24.15 & 36.17 & 0.41 & 0.00 \\
\hline 12 & 233 & 22.12 & 210.16 & 209.82 & 85.71 & 41.14 & 40.79 & 25.75 & 0.50 & 0.00 \\
\hline 13 & 65 & 27.78 & 61.62 & 61.40 & 88.72 & 16.79 & 16.53 & 36.51 & 0.35 & 0.04 \\
\hline 14 & 144 & 27.92 & 138.03 & 137.76 & 88.75 & 37.06 & 36.73 & 36.78 & 0.70 & 0.31 \\
\hline 15 & 94 & 31.99 & 95.03 & 94.79 & 87.59 & 33.71 & 33.37 & 44.99 & 0.36 & 0.04 \\
\hline 16 & 49 & 29.18 & 46.47 & 46.21 & 88.86 & 13.15 & 12.80 & 39.26 & 0.38 & 0.00 \\
\hline 17 & 152 & 28.02 & 151.76 & 151.49 & 88.77 & 40.40 & 40.06 & 36.98 & 0.35 & 0.00 \\
\hline 18 & 14 & 27.76 & 12.78 & 12.51 & 88.71 & 3.73 & 3.40 & 36.47 & 0.47 & 0.09 \\
\hline 19 & 295 & 25.50 & 281.69 & 281.43 & 87.87 & 67.44 & 67.14 & 32.12 & 0.40 & 0.00 \\
\hline 20 & 318 & 29.82 & 310.84 & 310.58 & 88.79 & 92.90 & 92.56 & 40.52 & 0.59 & 0.24 \\
\hline 21 & 51 & 28.67 & 51.73 & 51.46 & 88.85 & 14.38 & 14.04 & 38.25 & 0.39 & 0.00 \\
\hline 22 & 615 & 24.90 & 596.39 & 596.11 & 87.56 & 135.83 & 135.51 & 30.99 & 0.43 & 0.00 \\
\hline 23 & 370 & 23.97 & 355.67 & 355.41 & 87.00 & 76.49 & 76.26 & 29.22 & 0.46 & 0.05 \\
\hline 24 & 104 & 29.79 & 106.19 & 105.98 & 88.80 & 31.12 & 30.84 & 40.47 & 0.47 & 0.17 \\
\hline 25 & 100 & 29.41 & 101.47 & 101.23 & 88.85 & 29.87 & 29.56 & 39.70 & 0.22 & 0.00 \\
\hline 26 & 190 & 29.30 & 185.80 & 185.57 & 88.85 & 52.87 & 52.57 & 39.50 & 0.40 & 0.08 \\
\hline 27 & 67 & 28.89 & 63.97 & 63.73 & 88.86 & 18.07 & 17.76 & 38.69 & 0.16 & 0.00 \\
\hline 28 & 124 & 30.20 & 118.37 & 118.12 & 88.70 & 36.26 & 35.92 & 41.30 & 0.35 & 0.00 \\
\hline 29 & 64 & 29.39 & 57.40 & 57.14 & 88.85 & 17.19 & 16.86 & 39.67 & 0.32 & 0.00 \\
\hline 30 & 132 & 18.78 & 122.57 & 122.28 & 82.87 & 20.25 & 19.99 & 19.57 & 0.55 & 0.00 \\
\hline
\end{tabular}

${ }^{a}$ Counting from Wolsong NPPs

${ }^{\mathrm{b}}$ Net (counts or $\mathrm{Bq} / \mathrm{cc}$ ) = Gross - Background

Table 3 Tritium and Carbon-14 Analysis at PWRs

\begin{tabular}{|c|c|c|c|c|c|c|c|c|c|c|c|c|}
\hline \multirow{3}{*}{ No. } & \multicolumn{4}{|c|}{$\begin{array}{c}\text { Tritium Analysis Windows: } \\
\text { Channels } 1 \sim 9 \\
\end{array}$} & \multicolumn{4}{|c|}{$\begin{array}{l}\text { Carbon-14 Analysis Windows: } \\
\text { Channels } 4 \sim 85 \\
\end{array}$} & \multicolumn{4}{|c|}{$\begin{array}{c}\text { Carbon-14 Analysis Windows: } \\
\text { Channels } 30 \sim 85 \\
\end{array}$} \\
\hline & \multicolumn{2}{|c|}{ Gross $(\mathrm{Bq} / \mathrm{cc})$} & \multicolumn{2}{|c|}{ Net $(\mathrm{Bq} / \mathrm{cc})$} & \multicolumn{2}{|c|}{ Gross $(\mathrm{Bq} / \mathrm{cc})$} & \multicolumn{2}{|c|}{$\operatorname{Net}(\mathrm{Bq} / \mathrm{cc})$} & \multicolumn{2}{|c|}{ Gross $(\mathrm{Bq} / \mathrm{cc})$} & \multicolumn{2}{|c|}{$\operatorname{Net}(\mathrm{Bq} / \mathrm{cc})$} \\
\hline & Before $^{a}$ & After $^{\mathrm{b}}$ & Before $^{a}$ & After $^{\mathrm{b}}$ & Before $^{a}$ & After $^{\text {b }}$ & Before $^{a}$ & After $^{\mathrm{b}}$ & Before $^{a}$ & After $^{\mathrm{b}}$ & Before $^{a}$ & After $^{b}$ \\
\hline 1 & 0.71 & 0.70 & 0.50 & 0.49 & 0.37 & 0.39 & 0.01 & 0.03 & 0.44 & 0.39 & 0.12 & 0.07 \\
\hline 2 & 0.47 & 0.57 & 0.26 & 0.36 & 0.38 & 0.39 & 0.02 & 0.03 & 0.36 & 0.33 & 0.04 & 0.01 \\
\hline 3 & 0.55 & 0.71 & 0.34 & 0.50 & 0.38 & 0.48 & 0.02 & 0.12 & 0.37 & 0.40 & 0.05 & 0.08 \\
\hline 4 & 0.43 & 0.49 & 0.22 & 0.28 & 0.38 & 0.39 & 0.02 & 0.03 & 0.37 & 0.35 & 0.05 & 0.03 \\
\hline 5 & 0.40 & 0.49 & 0.19 & 0.28 & 0.35 & 0.41 & 0.00 & 0.05 & 0.33 & 0.37 & 0.01 & 0.05 \\
\hline 6 & 1.37 & 1.64 & 1.16 & 1.43 & 0.59 & 0.62 & 0.23 & 0.26 & 0.41 & 0.49 & 0.09 & 0.17 \\
\hline 7 & 9.19 & 9.37 & 8.98 & 9.16 & 3.01 & 3.14 & 2.65 & 2.78 & 0.36 & 0.34 & 0.04 & 0.02 \\
\hline 8 & 0.50 & 0.49 & 0.29 & 0.28 & 0.34 & 0.43 & 0.00 & 0.07 & 0.29 & 0.37 & 0.00 & 0.05 \\
\hline 9 & 0.50 & 0.55 & 0.29 & 0.34 & 0.40 & 0.41 & 0.04 & 0.05 & 0.37 & 0.39 & 0.05 & 0.07 \\
\hline 10 & 0.00 & 0.44 & 0.00 & 0.23 & 0.00 & 0.43 & 0.00 & 0.07 & 0.00 & 0.33 & 0.00 & 0.01 \\
\hline
\end{tabular}

${ }^{\text {a }}$ Counting results in urine samples before radiation work.

${ }^{\mathrm{b}}$ Counting results in urine samples after radiation work. 


\section{Internal Exposure Possibility Evaluation}

As a result of the application of dual counting analysis to the urine samples of radiation workers at Wolsong NPPs, it was found that the measurement results of tritium activity almost corresponded to the previous measurement results of tritium activity. Thus, the validity of the dual counting analysis method was indirectly demonstrated. In the meantime, there was the crossover phenomenon, where the interchange of sections between tritium and carbon-14 counts occurred for the results of carbon-14 analysis when Channels $4 \sim 85$ were set for carbon-14 analysis. This caused an overestimation of the carbon-14 counts. On the other hand, the phenomenon of crossover of tritium counts was properly eliminated when Channels $30 \sim 85$ were set for carbon-14 analysis. In addition, it was found through dual counting analysis that the counting results of carbon-14 for the urine samples of radiation workers at PHWRs were always lower than MDA, and the likelihood of internal exposure to carbon-14 is extremely low. ${ }^{6,12)}$ Several measurements of tritium and carbon-14 activity on actual urine samples of radiation workers at PHWRs were conducted by applying the developed method for dual counting analysis of tritium and carbon-14. Table 2 shows some of the results of the dual counting analysis. ${ }^{6}$

The dual counting method for tritium and carbon-14 in workers' urine was carried out for radiation workers who participated in tasks where high radiation exposure was expected, such as the opening process of steam generators during the maintenance period at pressurized water reactors (PWRs). As a result, it was found that the tritium activity in the urine samples of radiation workers at PWRs indicated almost MDA levels, which was much lower than those at Wolsong NPPs (PHWRs). Thus, this result indirectly demonstrated that the likelihood of internal exposure to tritium at PWRs was extremely low. Furthermore, there was no detection of carbon-14. This result confirms that there was no carbon-14 in the urine samples of radiation workers at PWRs and that internal exposure to carbon-14 is unlikely to occur. ${ }^{2,6,12)}$ The results of the presence of tritium and carbon-14 for actual urine samples of radiation workers at Yonggwang NPPs (PWRs), by applying the developed method for dual counting analysis, are shown in Table 3.,6)

\section{Conclusion}

In this study, carbon-14 production was investigated in order to establish a methodology for internal exposure possibility evaluation of carbon-14 inhalation. Furthermore, a method for dual counting analysis of tritium and carbon-14 in urine samples of NPP workers was developed. Finally, the procedures for measuring tritium and carbon-14 activity were provided based on the results of the experiment and investigation.

The method for dual counting analysis of tritium and carbon-14 was developed by linking this method with the current method for single counting analysis of tritium. The effective channels of LSC were set as Channels $1 \sim 9$ for analyzing tritium and Channels $30 \sim 85$ for analyzing carbon-14. Then, the validity of the developed dual counting analysis was demonstrated by using several experiments. In the meantime, the radioactivity counting analysis of carbon-14 in the actual urine samples of radiation workers at PHWR was conducted by using the developed method for dual counting analysis. As a result, it was found that there was no internal exposure to carbon-14 at both PWRs and PHWRs.

\section{Acknowledgment}

This research was carried out with the financial support of Korea Hydro \& Nuclear Power Corporation.

\section{References}

1) D. W. Whillans and K. S. Thind, Internal Dosimetry for Short-Range Emitters, In: Health Physics Society 1995 Summer School (Radiation Protection at Nuclear Reactors), Medical Physics Publishing Madison, Wisconsin, (1995).

2) H. G. Kim, T. Y. Kong, S. J. Han, G. J. Lee, "Development of the Dual Counting and Internal Dose Assessment Method for Carbon-14 at Nuclear Power Plants," J. Radiation Protection, 34[2], 55-64 (2009).

3) Korea Electric Power Corporation, Final Safety Analysis Report for Wolsong Unit 2,3,4 Nuclear Power Plants, Rev. 31, (2000).

4) Korea Electric Power Corporation, Final Safety Analysis Report for Yonggwang Unit 3,4 Nuclear Power Plants, (2000).

5) Korea Electric Power Corporation, Final Safety Analysis Report for Ulchin Unit 3,4 Nuclear Power Plants, (2000).

6) Korea Hydro \& Nuclear Power Corporation, Development on the C-14 Internal Dosimetry for Nuclear Power Plant Workers, (2008).

7) H. G. Kim, H. S. Lee, G. H. Ha, "An Analysis of Carbon-14 Metabolism for Internal Dosimetry at CANDU Nuclear Power Plants," Radiation Protection Dosimetry, 28[3], 207-213 (2003).

8) T. Y. Kong and H. G. Kim, "Preliminary Study on the Internal Dosimetry Program for Carbon-14 at Korean CANDU Reactors," Proc. Korean Nuclear Society Fall Meeting, (2005).

9) H. G. Kim, "Internal Dose Assessment of Carbon-14 at Korean CANDU Reactors," Proc. Korean Association of Radiation Protection Spring Meeting, (2006).

10) Korea Hydro \& Nuclear Power Corporation, Procedure for the Tritium Internal Dosimetry at Wolsong Nuclear Power Plant, (2008).

11) S. J. Han, G. J. Lee, T. Y. Kong, H. G. Kim, "Dual Counting Method for Tritium and ${ }^{14} \mathrm{C}$ Using Urine Samples of Radiation Workers," Proc. Korean Association of Radiation Protection Fall Meeting, (2008).

12) Korea Electric Power Research Institute, Technical Report of the Analysis Method of Tritium and C-14 in Urine Samples of Radiation Workers, Technical Memo, (2007). 